Brazilian Journal

of Chemical

ISSN 0104-6632

Printed in Brazil

Engineering

www.scielo.br/bjce

Vol. 35, No. 02, pp. 575 - 586, April - June, 2018

dx.doi.org/10.1590/0104-6632.20180352s20160172

\title{
DEPENDENCY OF NANOFLUID RHEOLOGY ON PARTICLE SIZE AND CONCENTRATION OF VARIOUS METAL OXIDE NANOPARTICLES
}

\author{
Kerim Yapici ${ }^{1 *}$, Ozge Osturk ${ }^{2}$ and \\ Yusuf Uludag ${ }^{3}$ \\ ${ }^{1}$ Department of Chemical Engineering, Suleyman Demirel University, 32260 Isparta, \\ Turkey \\ ${ }^{2}$ Department of Chemical Engineering, Cumhuriyet University, 58140 Sivas, Turkey \\ ${ }^{3}$ Department of Chemical Engineering, Middle East Technical University, 06800 \\ Ankara, Turkey
}

(Submitted: March 14, 2016; Revised: December 8, 2016; Accepted: January 20, 2017)

\begin{abstract}
Impact of the nanoparticle size and concentration on the rheology of ethylene glycol based nanofluids containing nanoparticles of five different metal oxides is investigated. Particle mass concentrations ranged from 5 to $20 \mathrm{wt} \%$. Types of the nanoparticles and their particle size are $\mathrm{TiO}_{2}(30 \mathrm{~nm}, 50 \mathrm{~nm}), \mathrm{MgO}(20 \mathrm{~nm}, 40$ $\mathrm{nm}), \mathrm{ZnO}(10-30 \mathrm{~nm}, 35-45 \mathrm{~nm}, 80-200 \mathrm{~nm}), \mathrm{SiO}_{2}(20-30 \mathrm{~nm}, 60-70 \mathrm{~nm})$ and $\mathrm{CuO}(40 \mathrm{~nm}, 80 \mathrm{~nm})$. A stress controlled rheometer fitted with a cone-and-plate system is employed for the rheological characterization of the nanodispersions at temperatures between $-5^{\circ} \mathrm{C}$ and $35^{\circ} \mathrm{C}$. The non-linear measurements reveal that nanofluids of $\mathrm{CuO}(40 \mathrm{~nm}), \mathrm{ZnO}(10-30 \mathrm{~nm}, 35-45 \mathrm{~nm})$ and $\mathrm{MgO}(20 \mathrm{~nm}, 40 \mathrm{~nm})$ particles exhibit non-Newtonian shear thinning behavior at particle mass concentrations higher than $5 \%$. No appreciable shear thinning is observed for the dispersions of $\mathrm{TiO}_{2}(30 \mathrm{~nm}, 50 \mathrm{~nm})$ and $\mathrm{SiO}_{2}(20-30 \mathrm{~nm}, 60-70 \mathrm{~nm})$ particles. Strong dependency between relative viscosity of the suspensions and particle size and loading is observed. Temperature, on the other hand, plays a marginal role in the relative viscosity of the suspensions. The shear viscosity measurements indicated the presence of particle size and concentration dependent apparent yield stress for $\mathrm{CuO}$ and $\mathrm{ZnO}$ nanofluids. Investigated nanofluids do not exhibit any thixotropy during their rheological characterization. Finally, viscoelastic measurements suggest that nanofluids are free of gel formation.
\end{abstract}

Keywords: Rheology, nanoparticles, size effect, nanofluids, non-Newtonian fluid.

\section{INTRODUCTION}

Due to their unique properties and potentially wide range of application (Wong and Leon, 2010; Taylor et al., 2013) the number of studies on nanofluids has increased in recent years. Most of these studies are devoted to the measurement of thermal behavior of nanofluids in order to cultivate their superior heat transfer properties compared to conventional fluids (Eastman et al., 2001; Xuan and Li, 2003). Since application of the nanofluids involves their flow, knowledge of their rheological properties become 
also crucial in the design or operation of such systems. In a recent review by Mahbubul et al. (2012), the effects of parameters including particle size and shape, particle concentration and temperature on nanofluid viscosity are covered. Similarly, in his review study, Rudyak (2013) considered the dependence of the nanofluid viscosity on particle concentration, size and temperature. He reported that the size of the particles had the strongest impact on the nanofluid rheology.

The effect of nanoparticle size on nanofluid viscosity has been the subject of many studies, as shown in Table 1, along with material, size and concentration of the particles, and dispersion medium. It is possible to deduce the following conclusions from Table1. Among the investigated metal oxides, $\mathrm{SiO}_{2}$ and $\mathrm{Al}_{2} \mathrm{O}_{3}$ are most widely used in the studies. In the majority of the studies, nine out of the twelve to be exact, a reduction in nanofluid viscosity with increasing nanoparticle size was observed. Meanwhile, it should be noted that investigating nanofluid rheology is not the primary objective of a number of studies in the Table. For instance, in the experimental studies conducted by Anoop et al. (2009) and He et al. (2007) the effect of particle size on the convective heat transfer in the laminar developing region was considered. For this purpose, Anoop et al. (2009) employed $\mathrm{Al}_{2} \mathrm{O}_{3} /$ water nanofluids with the average particle size of $45 \mathrm{~nm}$ and $150 \mathrm{~nm}$. Their experiments revealed that the relative

Table 1. Summary of earlier studies on the dependence of nanofluid viscosity on nanoparticle size.

\begin{tabular}{|c|c|c|c|c|c|}
\hline References & Particles & $\begin{array}{l}\text { Average particle size } \\
\text { (nm) }\end{array}$ & Based fluids & $\%$ Volume & Observation \\
\hline Namburu et al. (2007) & $\mathrm{SiO}_{2}$ & $20,50,100$ & 60:40 EG:W & $0-10$ & $\begin{array}{c}\text { The viscosity decreases } \\
\text { with increasing } \\
\text { nanoparticle size }\end{array}$ \\
\hline Chevalier et al. (2007) & $\mathrm{SiO}_{2}$ & $35,94,190$ & Ethanol & $1.4,7$ & $\begin{array}{c}\text { The viscosity decreases } \\
\text { with increasing } \\
\text { nanoparticle size }\end{array}$ \\
\hline Zhao et al. (2009) & $\mathrm{SiO}_{2}$ & $7,12,16,20,40$ & Water & $0.1-2$ & $\begin{array}{c}\text { The viscosity } \\
\text { decreases with } \\
\text { increasing nanoparticle } \\
\text { diameter }\end{array}$ \\
\hline Rudyak et al. (2013) & $\mathrm{SiO}_{2}$ & $18.1,28.3,45.6$ & Ethylene glycol & $0.25-7$ & $\begin{array}{c}\text { The viscosity decreases } \\
\text { with increasing } \\
\text { nanoparticle size }\end{array}$ \\
\hline Timofeeva et al. (2010) & $\mathrm{SiC}$ & $16,29,66,90$ & Water & 4.1 & $\begin{array}{c}\text { The viscosity decreases } \\
\text { with increasing } \\
\text { nanoparticle size }\end{array}$ \\
\hline Chang et al. (2005) & $\mathrm{CuO}$ & $30,75,150$ & Water & $\mathrm{Na}$ & $\begin{array}{c}\text { The viscosity decreases } \\
\text { with increasing } \\
\text { nanoparticle size }\end{array}$ \\
\hline $\begin{array}{l}\text { Pastoriza-Gallego et al. } \\
\qquad(2011)\end{array}$ & $\mathrm{CuO}$ & $33 \pm 13,11 \pm 3$ & Water & $0.16-1.7$ & $\begin{array}{c}\text { The viscosity decreases } \\
\text { with increasing } \\
\text { nanoparticle size }\end{array}$ \\
\hline Anoop et al. (2009) & $\mathrm{Al}_{2} \mathrm{O}_{3}$ & 45,150 & Water & $0.26-1.61$ & $\begin{array}{c}\text { The viscosity decreases } \\
\text { with increasing } \\
\text { nanoparticle size }\end{array}$ \\
\hline Shanker et al. (2012) & $\mathrm{Al}_{2} \mathrm{O}_{3}$ & 24,45 & 70:30 Glycerol: Water & $0.001-0.1$ & $\begin{array}{c}\text { The viscosity decreases } \\
\text { with increasing } \\
\text { nanoparticle size }\end{array}$ \\
\hline He et al. (2007) & $\mathrm{TiO}_{2}$ & $95,145,210$ & Water & 0.6 & $\begin{array}{c}\text { The viscosity increases } \\
\text { with increasing } \\
\text { nanoparticle size }\end{array}$ \\
\hline Nguyen et al. (2007) & $\mathrm{Al}_{2} \mathrm{O}_{3}$ & 36,47 & Water & $1-12$ & $\begin{array}{l}\text { At high particle } \\
\text { concentrations, } \\
\text { viscosities of } 47 \mathrm{~nm} \\
\text { particles are found to } \\
\text { be higher than that of } \\
36 \mathrm{~nm}\end{array}$ \\
\hline Prasher et al. (2006) & $\mathrm{Al}_{2} \mathrm{O}_{3}$ & $27,40,50$ & Propylene glycol & $0.5-3$ & $\begin{array}{l}\text { The relative viscosity } \\
\text { is almost independent } \\
\text { of the particle size }\end{array}$ \\
\hline
\end{tabular}


viscosity and heat transfer coefficient of the nanofluid containing $45 \mathrm{~nm}$ particles were higher than those of $150 \mathrm{~nm}$ particles. An opposite trend was observed for the thermal conductivity of the nanofluids, i.e., lower thermal conductivity in the case of the smaller particles. However, there is no universal trend in the dependence of various thermophysical properties on the nanoparticle. For example, He et al. (2007) reported viscosity and heat transfer coefficient trends with respect to the changing particle size different than those of Anoop et al. (2009). They investigated the heat transfer behavior of water-based nanofluids containing $\mathrm{TiO}_{2}$ with powder mean diameters of $20,95,145$ and $210 \mathrm{~nm}$. They concluded that the effective thermal conductivity decreases with increasing particle size, while viscosity follows a reverse pattern. Interestingly, the convective heat transfer coefficient appeared to be virtually independent of the particle size. The other contradictory result for the dependence of nanofluid viscosity on nanoparticle size was reported by Nguyen et al. (2007). They observed that the viscosity of $\mathrm{Al}_{2} \mathrm{O}_{3} /$ water nanofluids containing $36 \mathrm{~nm}$ particles is smaller than that of the $47 \mathrm{~nm}$ particles provided that the particle volume fraction exceeds $5 \%$. In another report published by Prasher et al. (2006), results associated with the effect of particle diameter, particle volume fraction and temperature on the viscosity of $\mathrm{Al}_{2} \mathrm{O}_{3}$ /propylene glycol nanofluids are included. They suggest that the use of particles with different sizes of 27, 40 and $50 \mathrm{~nm}$ appears to have a negligible impact on the relative viscosity of the nanofluids.

In all of the other studies in Table 1, the nanofluid viscosity decreases with increasing particle size. For example Zhao et al. (2009) examined the viscosity of a $\mathrm{SiO}_{2} /$ water nanofluid with different particle diameters and $\mathrm{pH}$ values. They stressed the importance of nanoparticle size on the viscosity of nanofluids. They found that, as the nanoparticle size decreases, the viscosity of nanofluids increases. Namburi et al. (2007) investigated the viscosity and specific heat of

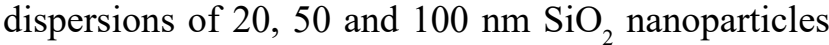
in ethylene glycol and water mixture with a weight ratio of 60:40, respectively. The experiments were performed at temperatures ranging from $-35^{\circ} \mathrm{C}$ to $50^{\circ} \mathrm{C}$. They observed a non-Newtonian shear thinning behavior for the $50 \mathrm{~nm} \mathrm{SiO}$, nanofluids at 6 volume $\%$ particle loading and at temperatures lower than $-10^{\circ} \mathrm{C}$. Moreover, they obtained nanofluids of the lowest viscosity with the largest particles, $100 \mathrm{~nm}$, at any temperature. Dispersions of the $\mathrm{SiO}_{2}$ nanoparticles with a wide particle diameter range from $7 \mathrm{~nm}$ to 190 $\mathrm{nm}$ were also examined by different research groups cited in Table 1 (Chevalier et al., 2007; Zhao et al., 2009; Rudyak et al., 2013). Interestingly, the nanofluids exhibit similar behavior of decreasing viscosity with respect to increasing particle size in spite of the different base fluids (ethanol, ethylene glycol, water, ethylene glycol and water mixture) employed.

In the studies listed in Table 1, the results of the viscosity measurements are not supplemented by possible mechanisms behind the dependence of the dispersion viscosity on the nanoparticle size, apart from the studies by Timofeeva et al. (2010) and Rudyak (2013). In their study Timofeeva et al. (2010) investigated the impact of the use of $\mathrm{SiC}$ particles having different diameters between 16 and $190 \mathrm{~nm}$ on the viscosity, thermal conductivity and heat transfer characteristics of SiC/water nanofluids. They observed that suspensions of smaller particles had higher viscosity than those of larger particles. They suggested that this phenomenon could stem from an electroviscous effect in connection with the effective volume of the particles in the suspension. They reported that the higher surface/volume ratio of smaller particles results in higher effective volume of the particles than larger particles. They concluded that higher effective particle volume of the smaller particles gives rise to the elevated viscosities compared to those of larger particle sizes.

Rudyak (2013), on the other hand, reported that, even at low particle concentrations, the distances between nanoparticles in suspension are on the order of their size. Hence, their hydrodynamic interactions should also be considered if an accurate model for nanofluid viscosity is to be developed. In his study Rudyak (2013) then proposed a model to capture the dependency of nanofluid viscosity on nanoparticle size and physical characteristics of the base fluid.

Almost all of the studies cited in Table 1 are devoted to the dependence of the nanofluid viscosity on the nanoparticle size. On the other hand, comprehensive studies of nanofluid rheology on particle size are lacking in the literature to the best of the knowledge of the authors. Hence, the objective of this study is to investigate the effect of various parameters including material type, particle size and temperature, on the rheology of nanofluids. The ethylene glycol based nanofluids used in this study were produced by using metal oxides of various sizes as tabulated in Table 2 . The particle concentration and temperature ranges were 5 to 20 weight $\%$ and $-5^{\circ} \mathrm{C}$ to $35^{\circ} \mathrm{C}$, respectively. 


\section{EXPERIMENTAL}

The nanoparticles employed in this study are $\mathrm{SiO}_{2}$ $\mathrm{CuO}, \mathrm{MgO}, \mathrm{ZnO}$ and $\mathrm{TiO}_{2}$. They were all commercially supplied by US Research Nanomaterial Inc. and used as purchased. Table 2 includes the specifications of the particles in terms of mean particle size, purity and specific surface area, all provided by the supplier. The base fluid, ethylene glycol (EG), was obtained from Sigma Aldrich.

To ensure stable dispersion and to prevent initial agglomeration of the nanoparticles in ethylene glycol, suspensions were agitated in an ultrasonic bath (Jeiotech, US-05, Korea) operated at $280 \mathrm{~W}$ and 40 $\mathrm{kHz}$ for six hours. No dispersal agent was used in the suspensions. All rheological measurements were carried out by means of a stress controlled rheometer (Malvern Kinexus Pro, UK) fitted with a cone-and-plate system. Diameter and angle of the cone were $60 \mathrm{~mm}$ and $1^{\circ}$, respectively. The gap between the cone-andplate was fixed at $0.05 \mathrm{~mm}$ during all measurements. A Peltier plate assembly was used for the temperature controlled measurements with $\pm 0.1^{\circ} \mathrm{C}$ precision.

Through the non-linear viscoelastic measurements, flow curves for the shear dependent viscosity of the nanofluids, temperature dependency of the viscosity, yield stress and thixotropic behavior of the nanofluids were probed. The yield stress value of the suspensions was determined by fitting the results to the HerschelBukley (HB) model given in Eq. (1).

$$
\tau=\tau_{0}+K_{\gamma}^{n}
$$

where $\tau_{0}$ is the yield stress $(\mathrm{Pa}), \mathrm{K}$ is the consistency index $\left(\mathrm{Pa} \mathrm{s}^{\mathrm{n}}\right)$ and $\mathrm{n}$ is the flow behavior index. Hysteresis loop areas were exploited to deduce any possible thixotropic behaviour of the suspensions (Benchabane and Bekkour, 2008). These experiments were performed in the shear rate range of 1 to 4000 $\mathrm{s}^{-1}$. The linear viscoelastic experiments for creep and recovery measurements were carried out at $0.05 \mathrm{~Pa}$ stress applied for $120 \mathrm{~s}$. Creep measurements were recorded after another $120 \mathrm{~s}$ of recovery period at a constant temperature of $25^{\circ} \mathrm{C}$.

\section{RESULTS AND DISCUSSION}

In this study the effect of nanoparticle size on the rheology of ethylene glycol based nanofluids containing five different oxide nanoparticles are investigated by linear and non-linear viscoelastic measurements. All of the nanofluids examined in this study were formulated over a $5-20 \mathrm{wt} \%$ particle mass fraction range. To compare our results with those available in the literature, particle mass fractions were converted to particle volume fractions and their

Table 2. Specifications of the nanoparticles used in this study.

\begin{tabular}{|c|c|c|c|}
\hline Particles & Mean particle size $(\mathrm{nm})$ & Purity & $\operatorname{SSA}\left(\mathrm{m}^{2} / \mathrm{g}\right)$ \\
\hline \multirow[b]{2}{*}{$\mathrm{SiO}_{2}$} & $20-30$ & \multirow{2}{*}{$99 \%$} & $180-600$ \\
\hline & $60-70$ & & $160-600$ \\
\hline \multirow{2}{*}{$\mathrm{CuO}$} & 40 & \multirow{2}{*}{$99 \%$} & 20 \\
\hline & 80 & & $>18$ \\
\hline \multirow{2}{*}{$\mathrm{MgO}$} & 20 & \multirow{2}{*}{$99 \%$} & $>60$ \\
\hline & 40 & & 25 \\
\hline \multirow{3}{*}{$\mathrm{ZnO}$} & $10-30$ & \multirow{3}{*}{$99 \%$} & $20-60$ \\
\hline & $35-45$ & & 65 \\
\hline & $80-200$ & & $4.8-6.8$ \\
\hline \multirow{2}{*}{$\mathrm{TiO}_{2}$} & 30 & \multirow{2}{*}{$99.9 \%$} & $35-60$ \\
\hline & 50 & & $20-40$ \\
\hline
\end{tabular}

SSA: Specific surface area

Table 3. Mass and corresponding volume percentages of the nanoparticles used.

\begin{tabular}{|c|c|c|c|c|c|}
\hline \multirow[t]{2}{*}{$\%$ mass } & \multicolumn{5}{|c|}{$\%$ volume } \\
\hline & $\mathrm{SiO}_{2}$ & $\mathrm{CuO}$ & $\mathrm{MgO}$ & $\mathrm{ZnO}$ & $\mathrm{TiO}_{2}$ \\
\hline 5 & 2.37 & 0.90 & 1.61 & 1.03 & 1.36 \\
\hline 10 & 4.88 & 1.89 & 3.33 & 2.15 & 2.83 \\
\hline 15 & 7.54 & 2.96 & 5.19 & 3.38 & 4.42 \\
\hline 20 & 10.36 & 4.15 & 7.19 & 4.72 & 6.15 \\
\hline
\end{tabular}


corresponding values for the nanofluids are tabulated in Table 3.

Within the range of temperature studied, $-5^{\circ} \mathrm{C}$ to $35^{\circ} \mathrm{C}$, ethylene glycol (EG) exhibits Newtonian behavior, characterized by a constant viscosity with respect to shear rate, as shown in Fig. 1. Moreover, the viscosity of EG decreases with increasing temperature as expected. The impact of temperature

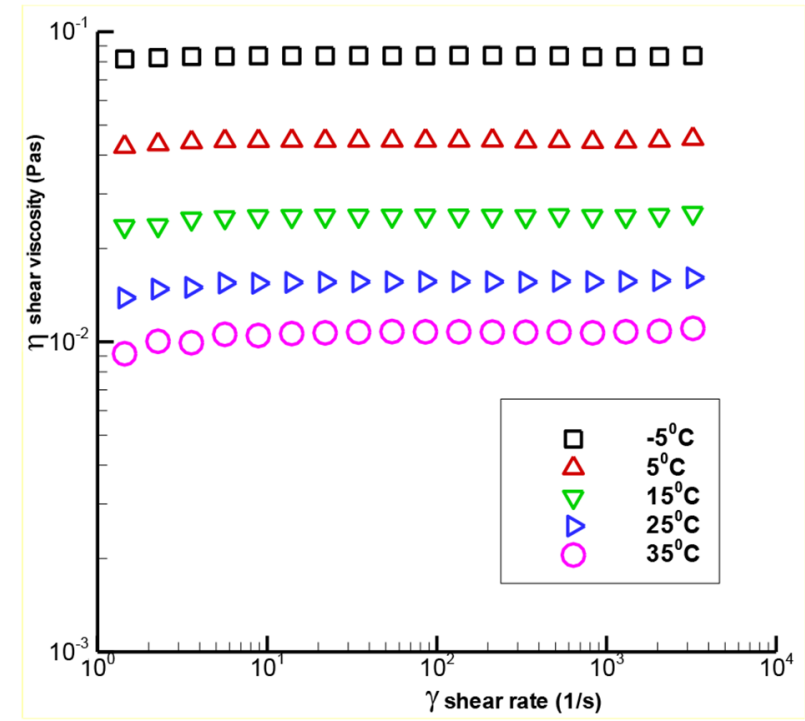

Figure 1. Shear viscosity versus shear rate for ethylene glycol as a function of the temperature.

variation on viscosity becomes more pronounced at low temperatures.

The flow curves for shear dependent viscosity of the nanofluids containing five different metal oxide particles at $25^{\circ} \mathrm{C}$ are shown in Fig. 2. Another expected result is associated with particle size and the concentration effect on the dispersion viscosity. Smaller particles or higher particle loading translate into dispersions with higher viscosity. No such common feature is observed when the non-Newtonian behavior of the dispersions is considered. Earlier studies on the shear flow curve of nanofluids indicated that nanoparticle dispersions in Newtonian base fluids exhibit either Newtonian or shear-thinning behavior depending on the material, size, shape, particle concentration, temperature and type of the base fluid (Mahbubul et al., 2012). Non-Newtonian feature of nanofluids can be attributed to the shear induced breaking of the larger fractal-like aggregates formed by sufficiently strong van der Waals forces between particles. Shear dependent viscosity curves in Fig. 2 suggest that van der Waals interactions favor formation of aggregates when nanoparticles of $\mathrm{ZnO}$,
$\mathrm{CuO}$ and $\mathrm{MgO}$ are used. On the other hand, attractive forces between particles of $\mathrm{TiO}_{2}$ and $\mathrm{SiO}_{2}$ seem to be insufficient to form aggregates, at least to a degree necessary to result in non-Newtonian dispersions in the studied ranges of particle size and concentration. The results depicted in Fig. 2 also signify the crucial role of particle size and concentration on the rheology of the dispersions. Clearly, an increasing concentration of particles translates into stronger impact on the flow behavior of the dispersions. Therefore, it is not a coincidence that the non-Newtonian nature of $\mathrm{ZnO} /$ $\mathrm{EG}, \mathrm{CuO} / \mathrm{EG}$ and $\mathrm{MgO} / \mathrm{EG}$ dispersions becomes more pronounced at higher concentrations, as shown in Fig. 2. This trend is very strong for $\mathrm{ZnO} / \mathrm{EG}$ and $\mathrm{CuO} / \mathrm{EG}$, while the overall change in the rheology of $\mathrm{MgO} / \mathrm{EG}$ dispersions remains relatively modest. When large particles are used, e.g., 80-200 nm $\mathrm{ZnO}$ particles, no change in the dispersion viscosity is observed with respect to shear rate in the 5 to $20 \mathrm{wt} \%$ particle concentration range.

The aggregation tendencies of the dispersions can be used to infer their stability. The likelihood of dispersions with lower aggregation degree being stable may be higher than those with a stronger aggregation tendency. In this case, dispersions of $\mathrm{ZnO} / \mathrm{EG}$ and $\mathrm{CuO} / \mathrm{EG}$ may turn out to be the least stable among the investigated oxides. No abrupt variation in the shear flow curves for all studied mass fractions may suggest that there was no stability issue for all particle loadings during the experiments. We believe that this point needs further clarification through stability experiments in the future.

In order to clearly reveal the impact of particle loading on the rheology of the dispersions, the results in Fig. 2 are also presented in terms of relative viscosity in Fig. 3. Relative viscosity is the ratio between the suspension and base fluid viscosities at a given flow condition. Fig. 3 depicts the variation of the relative viscosity with respect to particle concentration and size and shear rate at $25^{\circ} \mathrm{C}$ for the metal oxide dispersions in ethylene glycol base fluid. The shear flow curves in Fig. 2 show that suspensions containing $\mathrm{ZnO}, \mathrm{CuO}$ and $\mathrm{MgO}$ nanoparticles exhibit non-Newtonian shearthinning behavior. Hence, it is necessary to take the shear rate dependency of the relative viscosity into account. For this purpose relative viscosities of the nanofluids are evaluated at shear rates of $100 \mathrm{~s}^{-1}$ and $1000 \mathrm{~s}^{-1}$ and then presented in Fig. 3. Similar to Fig. 2 , an increase in relative viscosity at higher particle concentrations is captured in Fig. 3 for all particle sizes. When the effect of the particle size is concerned, the figure clearly depicts an increasing trend in relative 

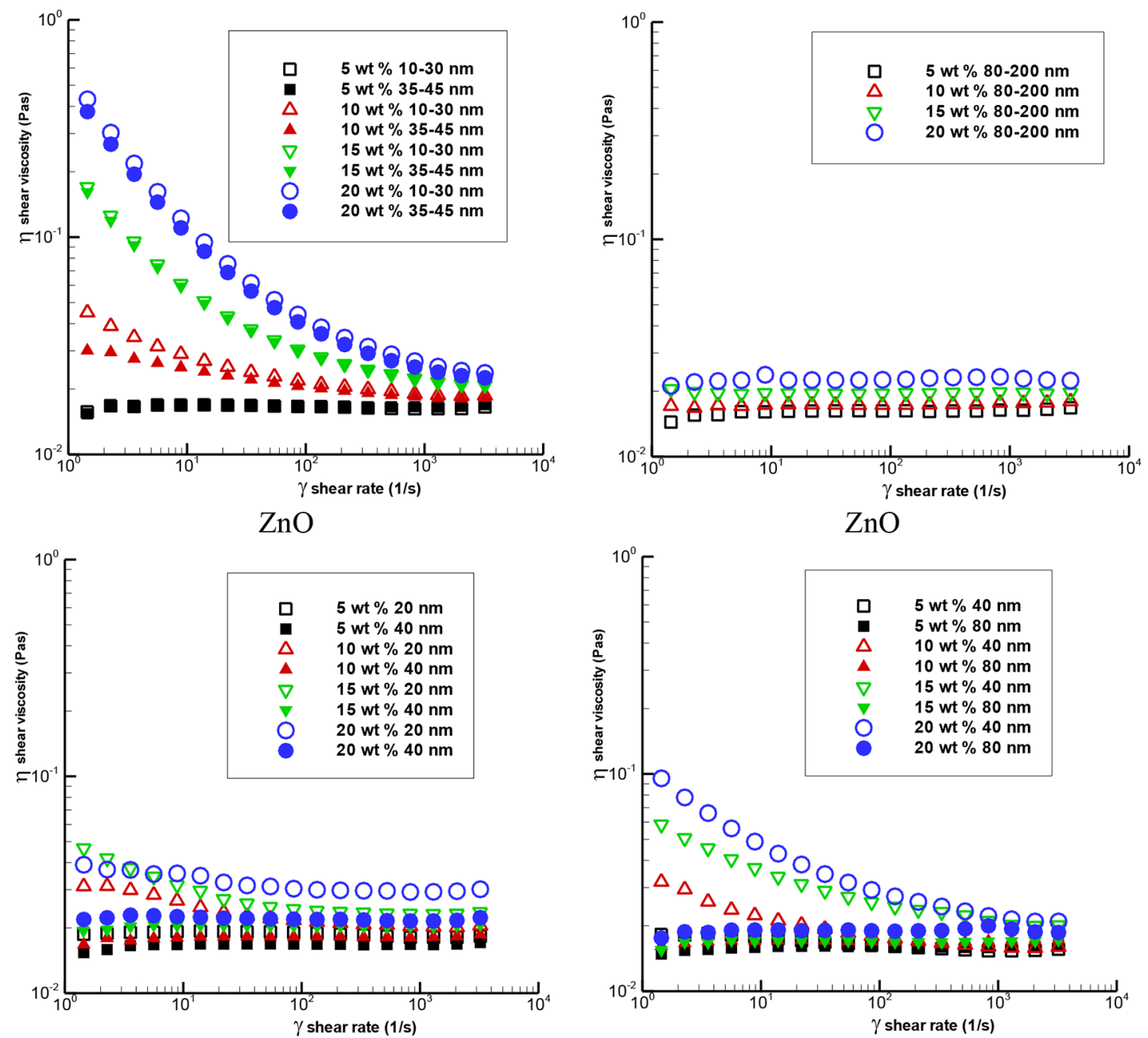

$\mathrm{MgO}$

$\mathrm{CuO}$

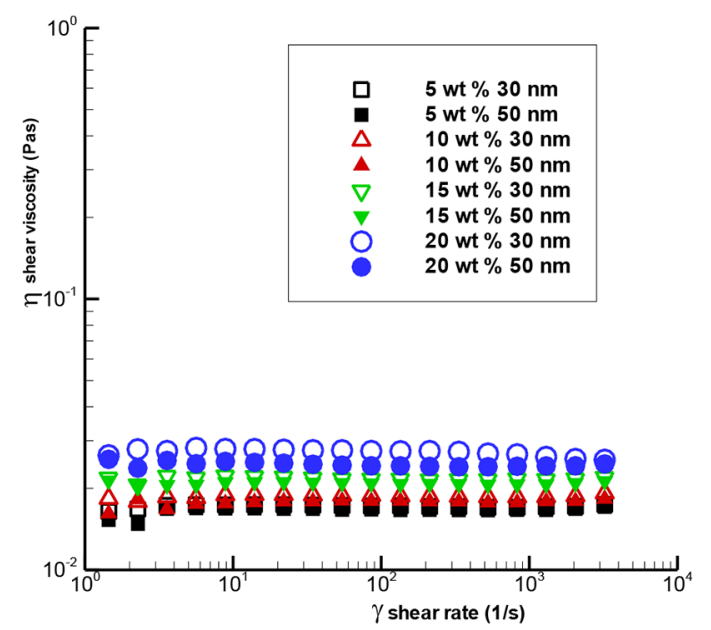

$\mathrm{TiO}_{2}$

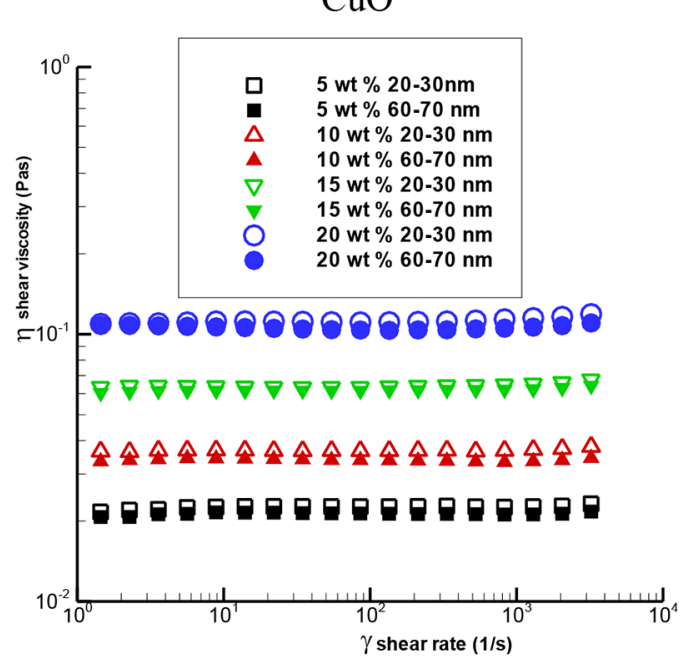

$\mathrm{SiO}_{2}$

Figure 2. Shear viscosity versus shear rate as a function of mass fractions at $25^{\circ} \mathrm{C}$. 

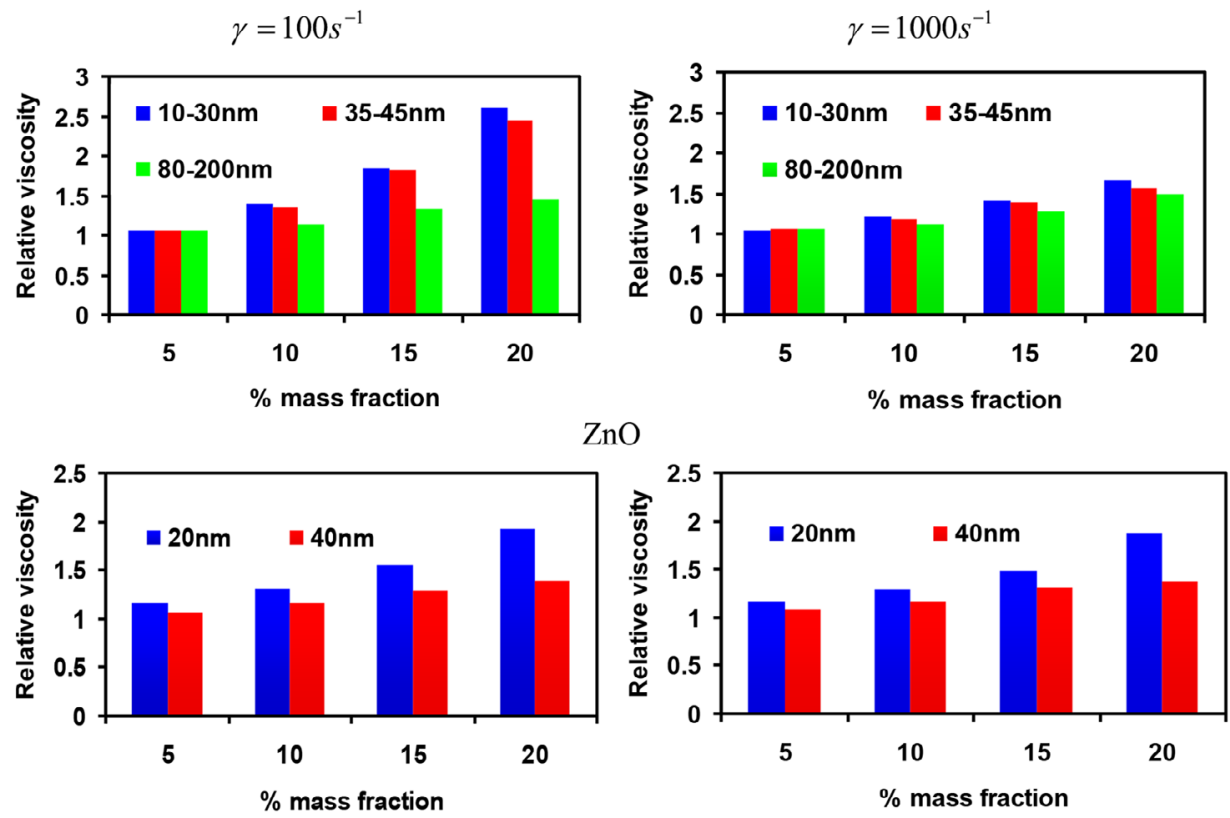

$\mathrm{MgO}$
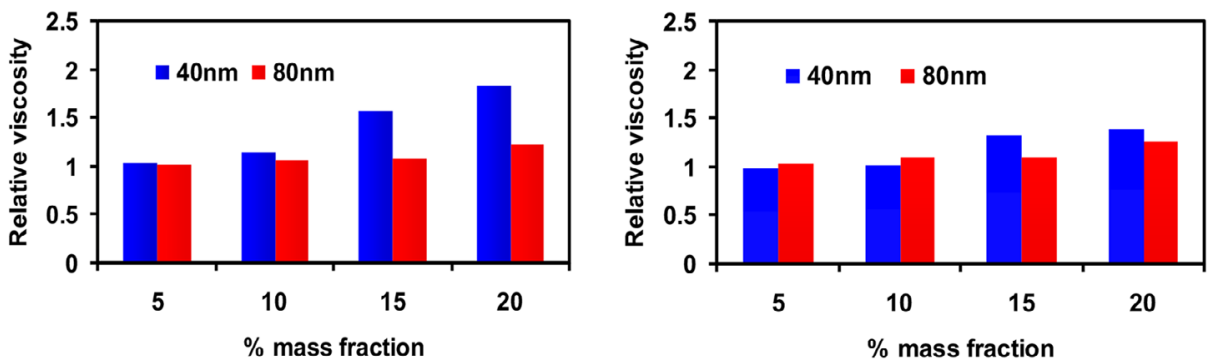

$\mathrm{CuO}$
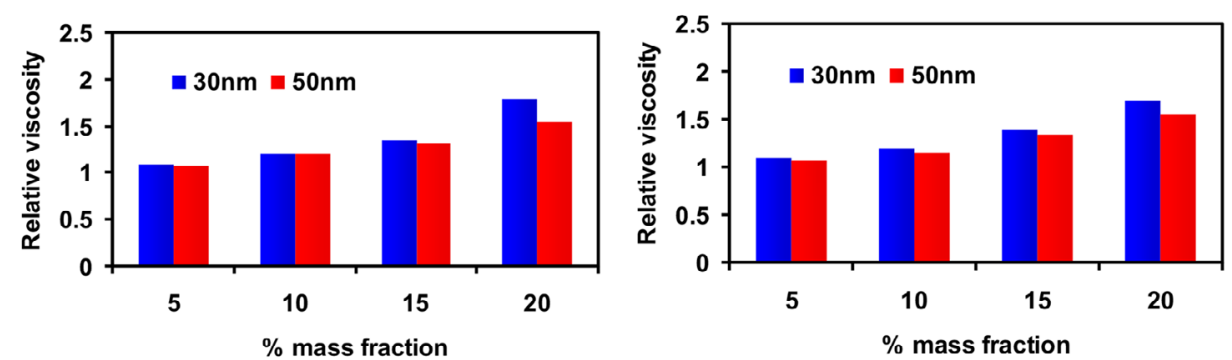

$\mathrm{TiO}_{2}$
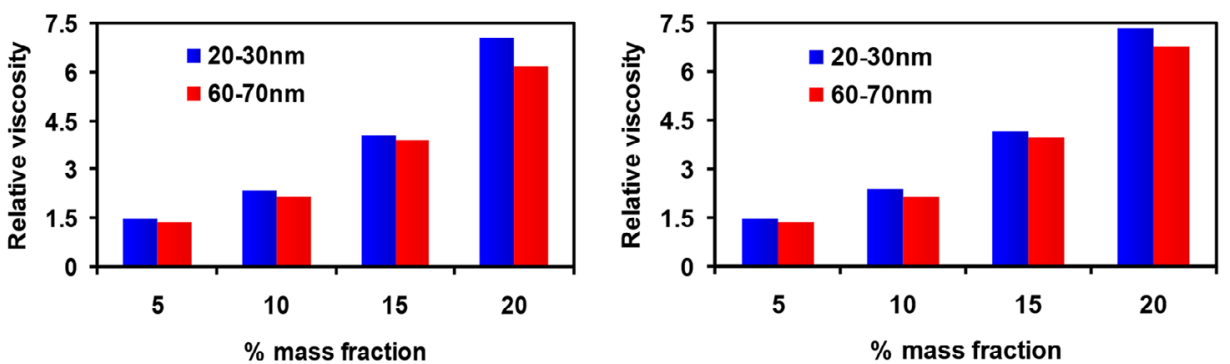

$\mathrm{SiO}_{2}$

Figure 3. Variation of the relative viscosity with respect to mass fraction at $25^{\circ} \mathrm{C}$. Note: The figures located in the left and right columns refer to viscosities obtained at shear rates $100 \mathrm{~s}^{-1}$ and $1000 \mathrm{~s}^{-1}$, respectively. 
viscosity in the case of smaller nanoparticles for all considered nanofluids. Impact of particle size becomes apparent at particle mass concentrations equal to or greater than $10 \%$. Type of the metal oxide also plays a role in the response of the nanofluid relative viscosity to the variations in the particle size. For instance, minimum and maximum reduction in relative viscosity is observed for $\mathrm{TiO}_{2}$ and $\mathrm{ZnO}$ nanofluids, respectively. The particle size vs. relative dispersion viscosity results that are presented in Fig. 3 are in agreement with most of the findings in earlier reports in Table 1. The authors of the present study agree with the following account suggested by Timofeeva et al. (2010) to explain the particle size effect on the relative viscosity. At a given particle mass concentration, the relative viscosity increases with decreasing particle size due to higher interfacial area, favoring stronger hydrodynamic interactions between solid and fluid phases. Stronger hydrodynamic interactions in turn result in higher resistance to flow or higher viscosity compared to the dispersions of larger particles.

In Fig. 3, comparison between the relative viscosities at two distinct shear rates of $100 \mathrm{~s}^{-1}$ and $1000 \mathrm{~s}^{-1}$ reveals the shear thinning behavior for the dispersions of $\mathrm{ZnO}, \mathrm{CuO}$ and $\mathrm{MgO}$ in $\mathrm{PE}$ base fluid. For the other metal oxides, i.e., $\mathrm{TiO} 2$ and $\mathrm{SiO} 2$, there is negligible, if any, variation in the relative viscosity underlying their Newtonian nature that is also depicted in Fig. 2.

Temperature is another important parameter influencing viscosity of the nanofluids. In their review article on nanofluid viscosity studies, Mahbubul et al. (2012) also considered the temperature dependence of nanofluid viscosity. They pointed out that the viscosity of nanofluids decreases at elevated temperatures. It is worthwhile to note that, in almost all of the studies on the temperature effect, dispersion viscosity was reported as opposed to the relative viscosity. Prasher et al. (2006) and Chen et al. (2007), on the other hand, investigated the dependenc of the nanofluid relative viscosity on temperature which turned out to be very weak. Fig. 4 shows the temperature effect on the relative viscosities of the dispersions of the metal oxides for different particle sizes and loadings at the shear rate of $100 \mathrm{~s}^{-1}$. The results are obtained by a series of rheological measurements that were conducted at temperatures ranging from $-5^{\circ} \mathrm{C}$ to $35^{\circ} \mathrm{C}$, with the increment of $10^{\circ} \mathrm{C}$. At low particle mass concentration, $5 \%$, relative viscosities remain nearly one, except for a modest increase in the case of $\mathrm{TiO}_{2}$ particles. With very limited impact of particles on the dispersion rheology, the relative viscosity becomes insensitive to variations in both particle size and temperature, as shown in the first column of Fig. 4 at low particle concentrations. On the other hand, at sufficiently high particle loadings, such as $20 \mathrm{wt} \%$, the relative viscosity significantly increases for all metal oxide dispersions within the studied range of experimental parameters. Furthermore, decreasing relative viscosities with increasing particle size are observed at $20 \%$ particle concentrations. Only a small increase in the relative viscosities of $\mathrm{ZnO} / \mathrm{EG}, \mathrm{CuO} / \mathrm{EG}$ and $\mathrm{TiO}_{2} /$ $\mathrm{EG}$ dispersions with respect to increasing temperature is observed, in spite of high particle loading, $20 \mathrm{wt} \%$. Therefore, it can be concluded that temperature does not play a significant role in the relative viscosity of dispersion, a conclusion similar to those drawn in the earlier studies of Prasher et al. (2006) and Chen et al. (2007).

To further the rheological characterization of the suspensions, their yield stress properties were also investigated. Fig. 5 shows logarithmic flow curves of shear viscosity with respect to shear stress for $\mathrm{ZnO}$ $(10-30 \mathrm{~nm}$ and $35-45 \mathrm{~nm})$ and $\mathrm{CuO}(40 \mathrm{~nm}$ and $80 \mathrm{~nm})$ nanoparticle dispersions in ethylene glycol up to 20 wt $\%$ concentration. The shear viscosity-stress curves in Fig. 5 suggest that the apparent yield stress gets stronger with decreasing particle size and increasing particle loading. Due to the observed shear thinning behavior and presence of apparent yield stress, the shear rate dependence of the $\mathrm{ZnO}$ and $\mathrm{CuO}$ nanofluid viscosities can be captured by the Herschel-Bulkley (HB) model. The model parameters that are predicted by fitting to the experimental results are listed in Table 4 for the range of particle size and concentrations considered here. The predicted yield stress of $\mathrm{ZnO}$ nanofluids increases as the particle size decreases, particularly at the high particle loading, $20 \mathrm{wt} \%$. The flow behavior index, $n$, that indicates the degree of dependence of viscosity on shear rate, is also tabulated in Table 4. The predicted values of $n$ appear to be a weak function of particle size, as shown in Table 4 . Thixotropic behavior of the nanofluids was also investigated by following the methodology suggested by Benchabane and Bakkour (2008). The results, not shown here, revealed no evidence of thixotropic behavior for any of the dispersions investigated in this study.

Finally, linear viscoelastic properties of the suspensions were examined in terms of creep test that measures time dependent deformation (Baek and Kim, 2011) by applying a shear stress of 0.05 Pa. Fig. 6 shows the creep compliance-time curve for nanofluids containing $\mathrm{ZnO}(10-30 \mathrm{~nm}$ and $35-45 \mathrm{~nm})$ and $\mathrm{CuO}$ 

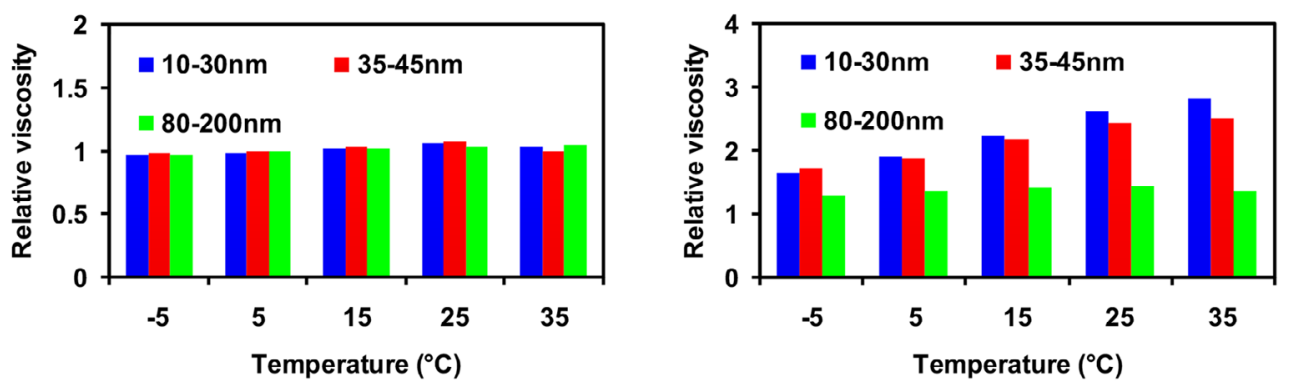

$\mathrm{ZnO}$
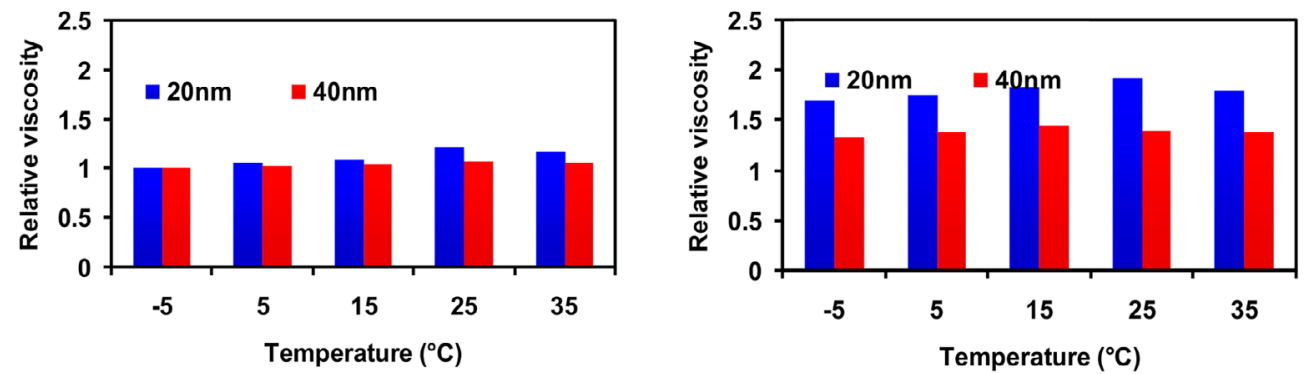

$\mathrm{MgO}$
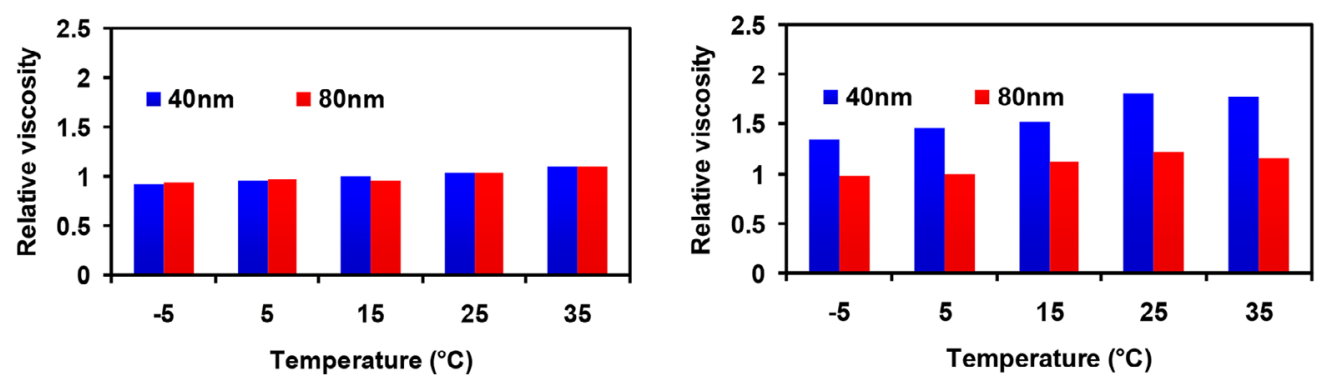

$\mathrm{CuO}$
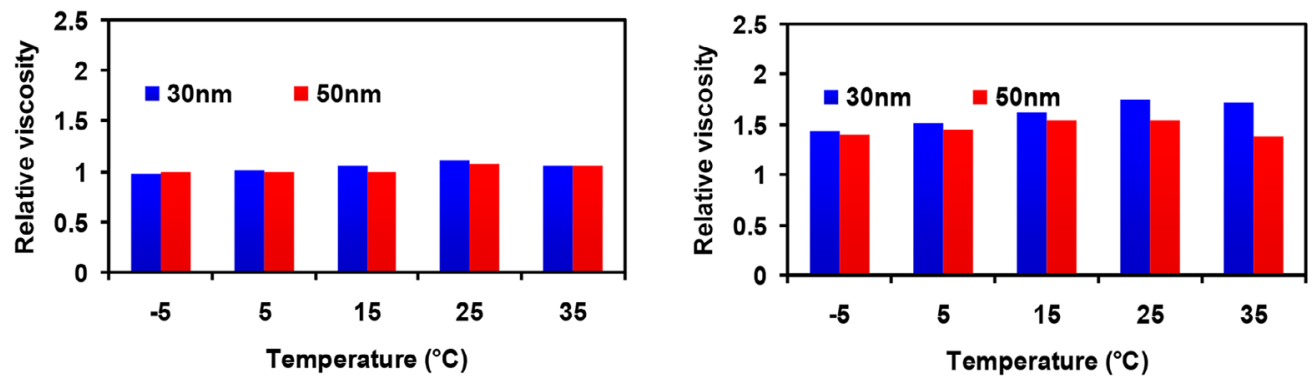

$\mathrm{TiO}_{2}$
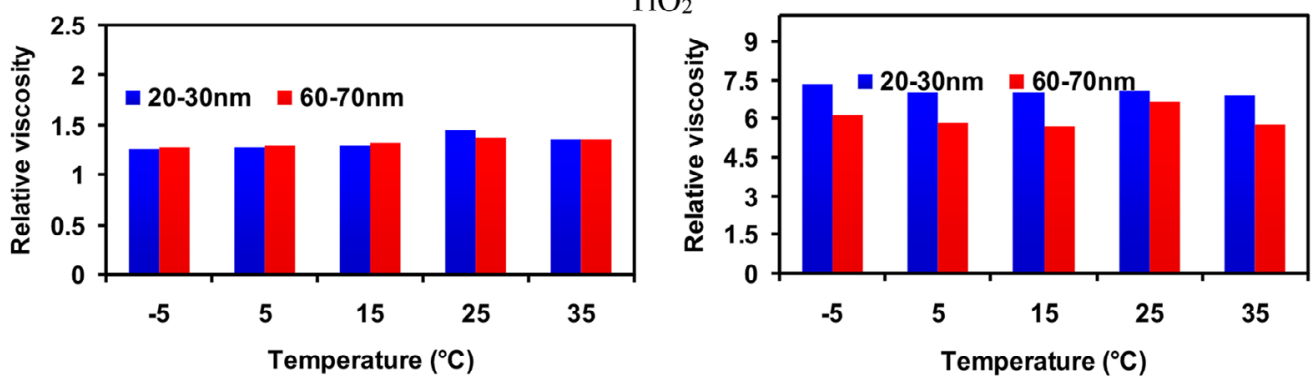

$\mathrm{SiO}_{2}$

Figure 4. Variation of the relative viscosity with respect to temperature. Note: The figures located in the left and right columns refer to relative viscosities for the particle mass fractions of 5 and $20 \mathrm{wt} \%$, respectively. 

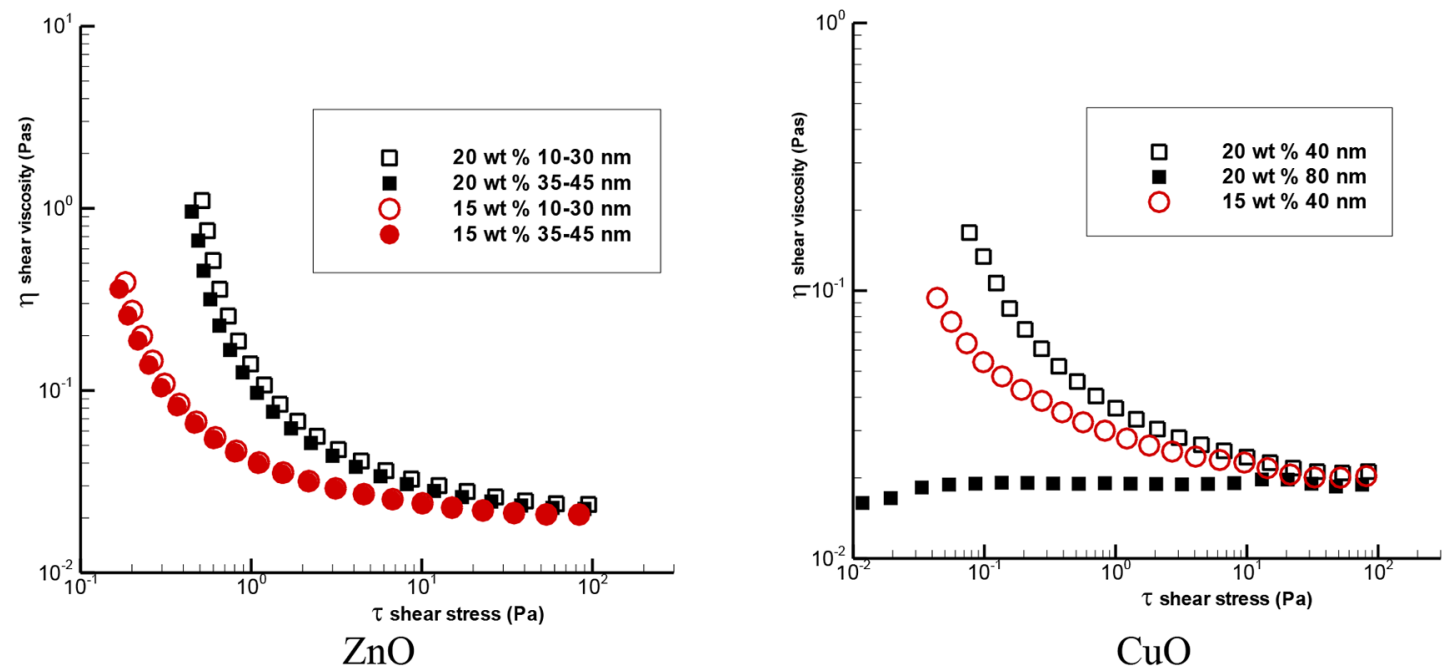

Figure 5. Shear viscosity versus shear stress for dispersions including $\mathrm{ZnO}$ and $\mathrm{CuO}$ at $25^{\circ} \mathrm{C}$.

Table 4. Variation of the predicted HB model parameters with respect to the particle size and mass percentage.

\begin{tabular}{ccccc}
\hline & & & ZnO & \\
\hline$\%$ mass & & $10-30 \mathrm{~nm}$ & $35-45 \mathrm{~nm}$ & $40 \mathrm{~nm}$ \\
\hline \multirow{2}{*}{20} & $\tau_{0}(\mathrm{~Pa})$ & 0.6133 & 0.5293 & 0.1945 \\
& $\mathrm{~K}$ & 0.0436 & 0.0402 & 0.0272 \\
& $\mathrm{n}$ & 0.9238 & 0.9272 & 0.9674 \\
& $\tau_{0}(\mathrm{~Pa})$ & 0.2745 & 0.0276 & 0.1385 \\
& $\mathrm{~K}$ & 0.0290 & 0.9645 & 0.0240 \\
& $\mathrm{n}$ & 0.9586 & & 0.9778 \\
\end{tabular}
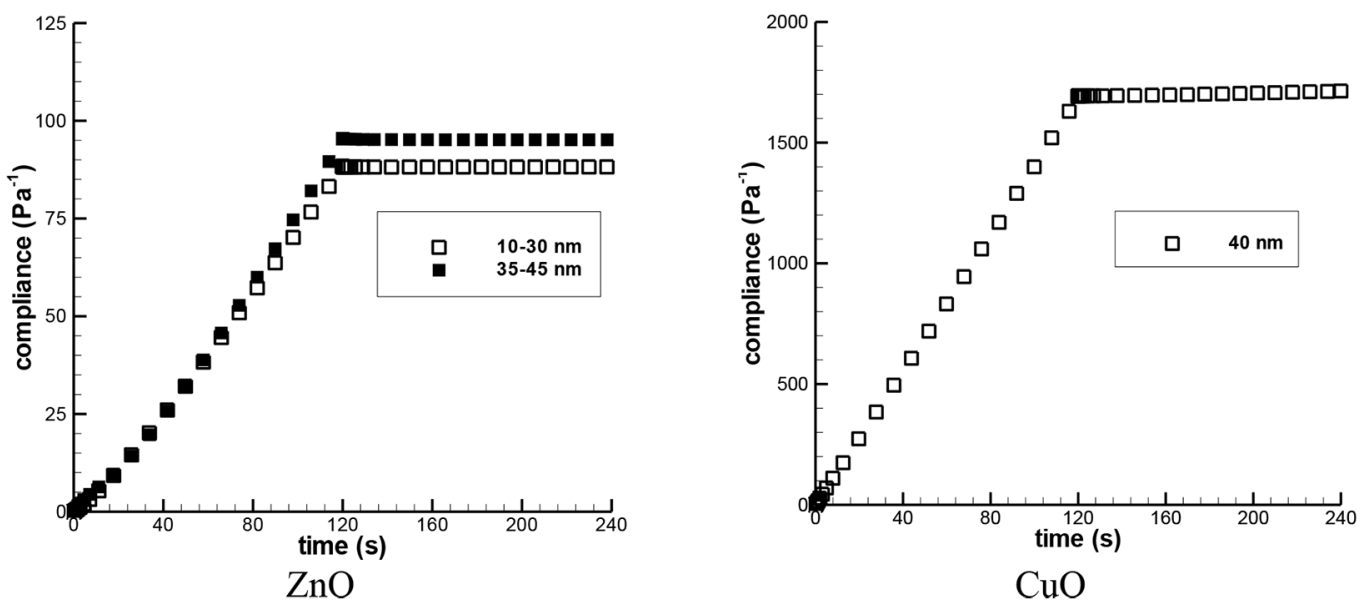

Figure 6. Creep and recovery curves for $\mathrm{ZnO}$ and $\mathrm{CuO}$ nanofluids containing $20 \mathrm{wt} \%$ particles at applied stresses of $0.05 \mathrm{~Pa}$. 
(40 $\mathrm{nm}$ and $80 \mathrm{~nm}$ ) nanoparticles at $20 \mathrm{wt} \%$ particle concentration. The compliance curves turned out to be similar to those typical of viscous fluids with no elasticity. Besides, the viscoelastic behavior of a material can be quantified by calculating the recovery index $\Delta J$ (Benchabane and Bekkour, 2008; Yapici et al., 2014) given in eq. (2). In this equation $J(120)$ and $J(240)$ refer to the values of the compliance at the final recovery phase and at the final creep phase, respectively.

$$
\Delta J=100 \frac{J(120)-J(240)}{J(120)}
$$

A $\Delta J$ value close to $100 \%$ is an indication a solid like structure, while decreasing values towards zero hint at increasing viscous material. The values of $\Delta \mathrm{J}$ for $\mathrm{ZnO}$ and $\mathrm{CuO}$ nanofluids containing $20 \mathrm{wt} \%$ particles are $0 \%$ indicating that the suspension exhibits viscous fluid properties. Therefore, non-Newtonian dispersions of $\mathrm{ZnO}$ and $\mathrm{CuO}$ do not appear to possess any gel structure that would otherwise manifest its presence through some degree of elasticity.

\section{CONCLUSIONS}

In this study effects of the nanoparticle size and loading on the rheology of ethylene glycol based nanofluids are presented. Nanoparticles of five different metal oxides were used over a 5-20 wt $\%$ particle mass concentration range. The nanoparticles and their sizes are $\mathrm{TiO}_{2}(30 \mathrm{~nm}, 50 \mathrm{~nm}), \mathrm{MgO}(20 \mathrm{~nm}$, $40 \mathrm{~nm}), \mathrm{ZnO}(10-30 \mathrm{~nm}, 35-45 \mathrm{~nm}, 80-200 \mathrm{~nm}), \mathrm{SiO}_{2}$ $(20-30 \mathrm{~nm}, 60-70 \mathrm{~nm})$ and $\mathrm{CuO}(40 \mathrm{~nm}, 80 \mathrm{~nm})$. All rheological measurements were carried out by a stress controlled rheometer equipped with a cone-and-plate system over a temperature range from $-5^{\circ} \mathrm{C}$ to $35^{\circ} \mathrm{C}$. The following conclusions can be drawn from the results of the measurements.

- The non-linear measurements reveal that among the nanofluids considered, only suspensions containing $\mathrm{CuO}(40 \mathrm{~nm})$ and $\mathrm{ZnO}(10-30$ $\mathrm{nm}, \quad 35-45 \mathrm{~nm})$ exhibit appreciable nonNewtonian shear thinning behavior at particle mass concentrations higher than $5 \mathrm{wt} \%$. Moreover, weak shear thinning is observed for the nanofluids of the smallest $\mathrm{MgO}$ particles $(20 \mathrm{~nm})$. These findings indicate that shearthinning behavior of nanofluids depends on the type of the material, particle diameter, as well as particle mass concentration.
- Formation and shear induced breaking of aggregates play a significant role in the shear thinning behavior of the dispersions.

- At a given particle mass concentration, an increase in dispersion viscosity is observed when smaller particles are used. This is most likely due to the stronger hydrodynamic interaction between the solid and liquid phases associated with the higher interfacial area provided.

- For all nanofluids considered in the present study, the relative viscosity decreases with increasing particle sizes. This reduction in relative viscosity becomes stronger at particle mass concentrations higher than $5 \mathrm{wt} \%$. In addition, the decay ratio of relative viscosity with particle size is dependent on the particle material type.

- Temperature variations have a limited effect on the relative viscosity of the suspensions.

- The shear viscosity measurements indicate the presence of an apparent yield stress for nanofluids of $\mathrm{CuO}$ and $\mathrm{ZnO}$ nanoparticles. The magnitude of the yield stress is observed to be dependent on both size and concentration of the nanoparticles.

- Among the nanofluids considered, no evidence of thixotropic behavior is observed at any particle concentrations.

- The results of the linear viscoelastic measurements do not suggest any elasticity or hence formation of a gel structure in any of the investigated nanofluids.

\section{ACKNOWLEDGEMENT}

The authors would like to gratefully acknowledge the funding from Scientific Research Project Fund of Cumhuriyet University under the project number M-490.

\section{REFERENCES}

Anoop, K.B., Sundararajan, T., Das, S.K., Effect of particle size on the convective heat transfer in nanofluid in the developing region, International Journal of Heat and Mass Transfer, 52(9-10), 21892195 (2009).

Baek, G., Kim, C., Rheological properties of Carbopol containing nanoparticles, Journal of Rheology, 55 313-330 (2011). 
Benchabane, A. and Bekkour, K., Rheological properties of carboxymethyl cellulose (CMC) solutions, Colloid and Polymer Science, 286 11731180 (2008).

Chang, H., Jwo, C.S. Lo., C.H. Tsung, T.T. Kao, M.J. Lin, H.M., Rheology of $\mathrm{CuO}$ nanoparticle suspension prepared by ASNSS, Rev. Adv. Mater. Sci., 10 128-132 (2005).

Chen, H., Ding, Y., Tan, C., Rheological behaviour of nanofluids, New Journal of Physics, 9, 367 (2007).

Chevalier, J., Tillement, O. Ayela, F., Rheological properties of nanofluids flowing through microchannels, Applied Physics Letters, 91, 233103 (2007).

Eastman, J.A., Choi, S.U.S., Li., S. Yu, W. Thompson, L.J., Anomalously increased effective thermal conductivities of ethylene glycol-based nanofluids containing copper nanoparticles, Applied Physics Letter, 78 718-720 (2001).

He, Y., Jin, Y. Chen, H. Ding, Y. Cang, D. Lu, H., Heat transfer and flow behaviour of aqueous suspensions of $\mathrm{TiO}_{2}$ nanoparticles (nanofluids) flowing upward through a vertical pipe, International Journal of Heat and Mass Transfer, 50 2272-2281 (2007).

Mahbubul, I.M., Saidur, R., Amalina, M.A., Latest developments on the viscosity of nanofluids, International Journal of Heat and Mass Transfer, 55 874-885 (2012).

Namburu, P.K., Kulkarni, D.P. Dandekar, A. Das, D.K., Experimental investigation of viscosity and specific heat of silicon dioxide nanofluids, Micro \& Nano Letters, 2 67-71 (2007).

Nguyen, C.T., Desgranges, F., Roy, G., Galanis, N., Maré, T., Boucher, S., Angue Mintsa, H., Temperature and particle-size dependent viscosity data for water-based nanofluids - Hysteresis phenomenon, International Journal of Heat and Fluid Flow, 28(6) 1492-1506 (2007).

Pastoriza-Gallego, M.J., Casanova, C., Legido, J.L., Piñeiro, M.M., $\mathrm{CuO}$ in water nanofluid: Influence of particle size and polydispersity on volumetric behaviour and viscosity, Fluid Phase Equilibria, 300(1-2), 183-196 (2011).
Prasher, R., Song, D., Wang, J., Phelan, P., Measurement of nanofluid viscosity and its implications for thermal applications, Applied Physics Letters, 89(13), 133108 (2006).

Rudyak, V.Y., Viscosity of nanofluids-Why it is not described by the classical theories, Advances in Nanoparticles, 2 266-279 (2013).

Rudyak, V.Y., Dimov, S.V., Kuznetsov, V.V. and Bardakhanov, S.P., Measurement of the viscosity coefficient of an ethylene glycol-based nanofluid with silicon di-oxide particles, Doklady Physics, 58 173-176 (2013).

Shanker, N.S., Reddy, M.C.S., Basava Rao, V.V., On prediction of viscosity of nanofluids for low volume fraction of nanoparticles, International Journal of Engineering Research \& Technology, 1 1-10 (2012).

Taylor, R., Coulombe, S., Otanicar, T., Phelan, P., Gunawan, A. Lv, W., Rosengarten, G., Prasher, R., Tyagi, H., Small particles, big impacts: A review of the diverse applications of nanofluids, Journal of Applied Physics, 113, 011301 (2013).

Timofeeva, E.V., Smith, D.S., Yu, W., France, D.M. Singh, D., and Routbort, J.L., Particle size and interfacial effects on thermo-physical and heat transfer characteristics of water-based $\alpha$-SiC nanofluids, Nanotechnology, 21(21), 215703 (2010).

Wong, K.V., Leon, O.M., Application of nanofluids: current and future, Advances in Mechanical Engineering, 2, 519659 (2010).

Xuan, Y., Li, Q., Investigation on convective heat transfer and flow features of nanofluids, Journal of Heat Transfer, Transaction of the ASME, 125 151155 (2003).

Yapici, K., Cakmak, N.K., Ilhan, N., Uludag, Y., Rheological characterization of polyethylene glycol based $\mathrm{TiO}_{2}$ nanofluids, Korea-Austrialia Rheology Journal, 26 335-363 (2014).

Zhao, J.F., Luo, Z.Y., Ni, M.J., Cen, K.F., Dependency of nanofluid viscosity on particle size and $\mathrm{pH}$ value, Chinese Physics Letters, 26, 066202 (2009). 